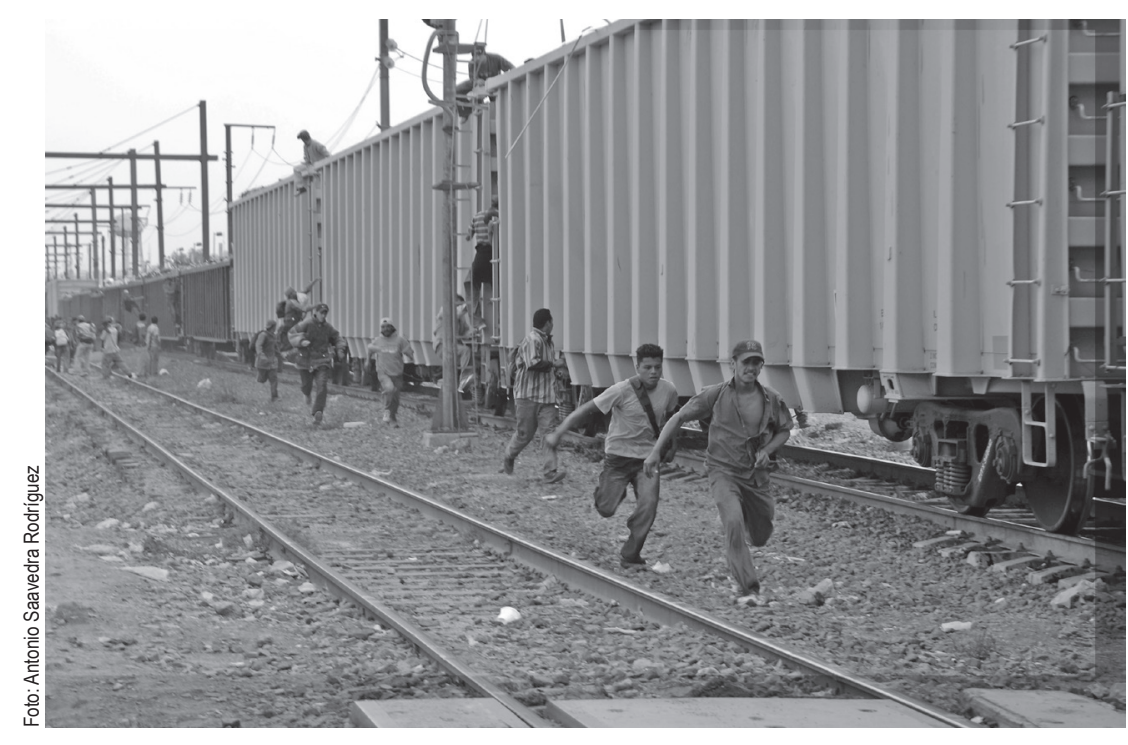

\section{La Bestia} transita por ríos y desiertos

Fotos de

Antonio Saavedra Rodríguez

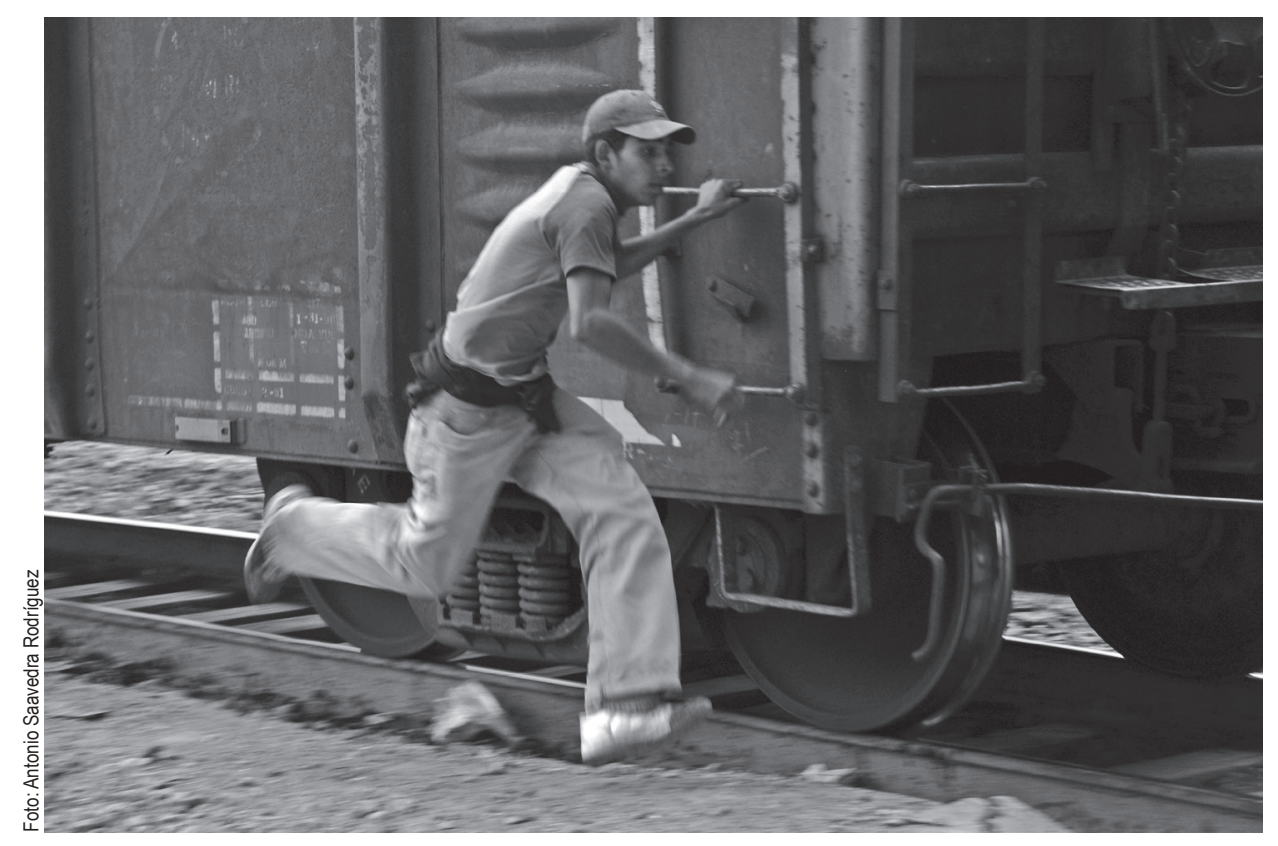

Antonio Saavedra Rodríguez es fotógrafo profesional, con más de 15 años de experiencia. Su trabajo lo ha realizado enfocado en los temas de derechos humanos y no discriminación.

En el año 2004 obtuvo mención honorífica en el concurso El México de los mexicanos.

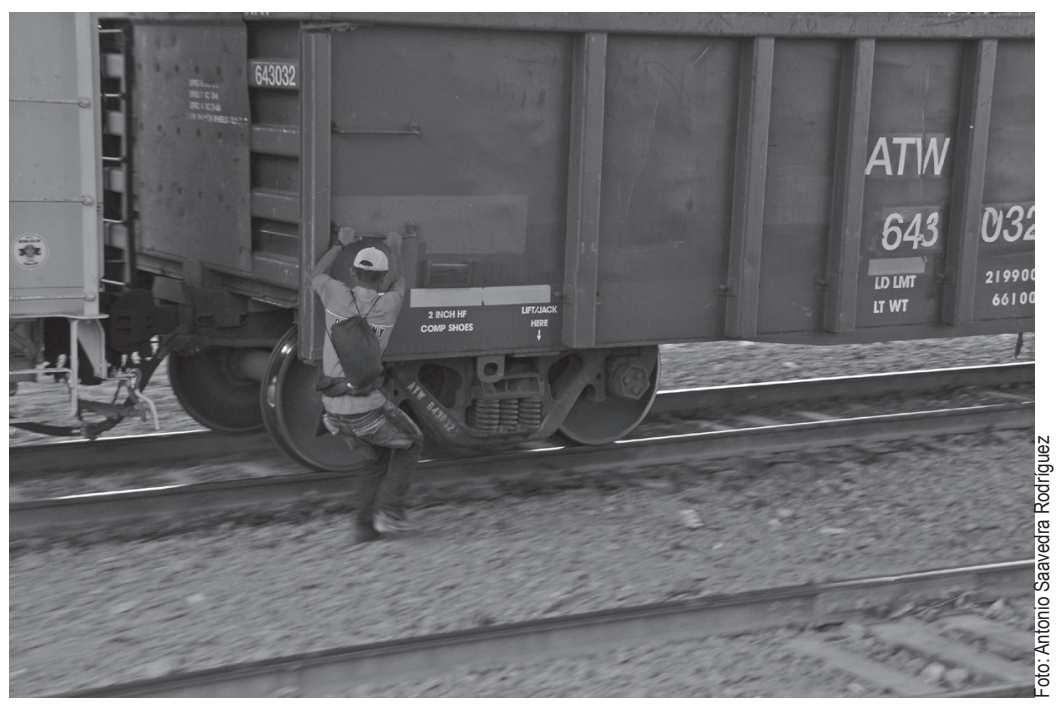




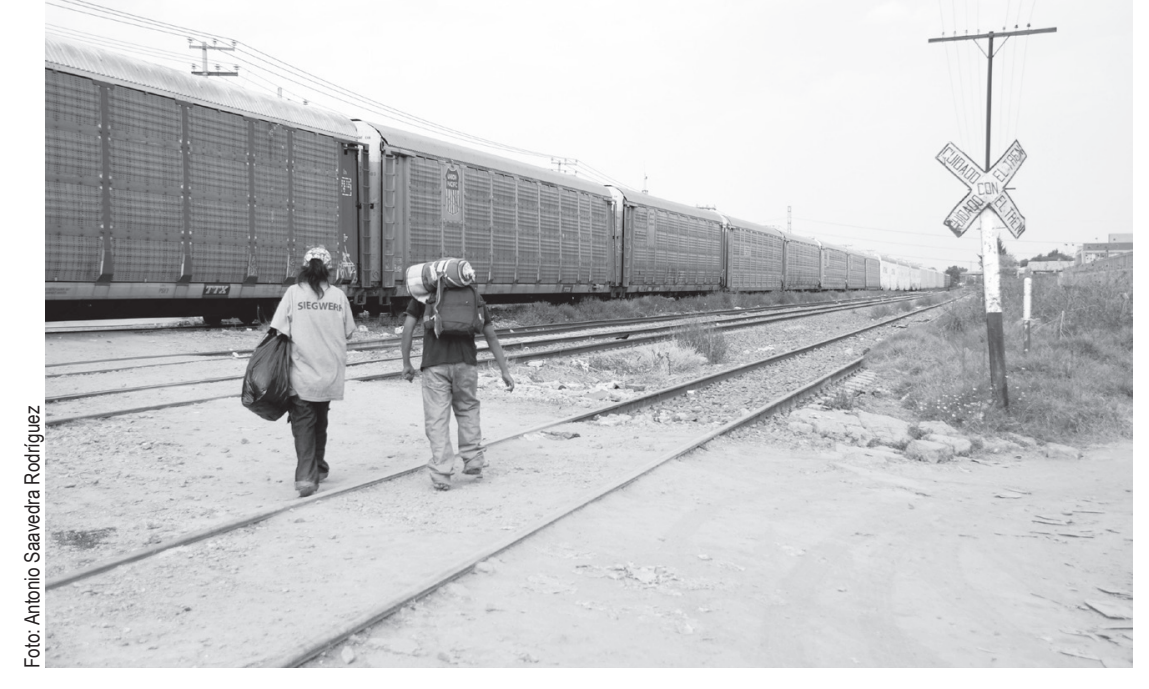

El hambre migra, no cabe duda.

La indefensión migra,

la violación a los elementales derechos humanos migra también.

El analfabetismo migra, la violencia migra.

En la bestia o no,

los motivos para alejarse del terruño y de su gente, se esconden cual criminales al acecho, listos para atacar y defender su existencia a perpetuidad, independientemente del lugar y del tiempo.

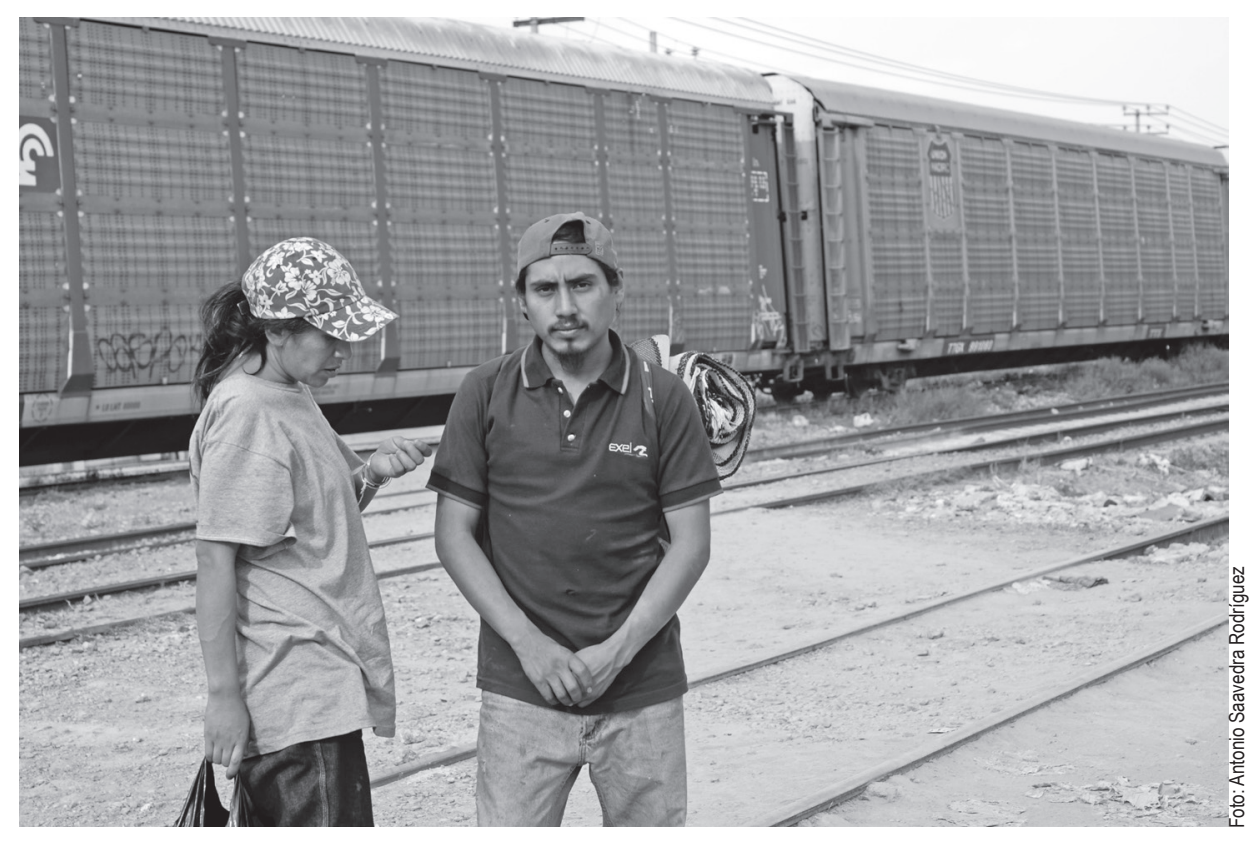

Realmente el origen y el destino es lo de menos, lo importante aquí es que las mujeres, hombres, niños, personas de la tercera edad llevan de equipaje sus tristezas, preocupaciones, desesperaciones, deterioros y vidas conflictuadas por años.

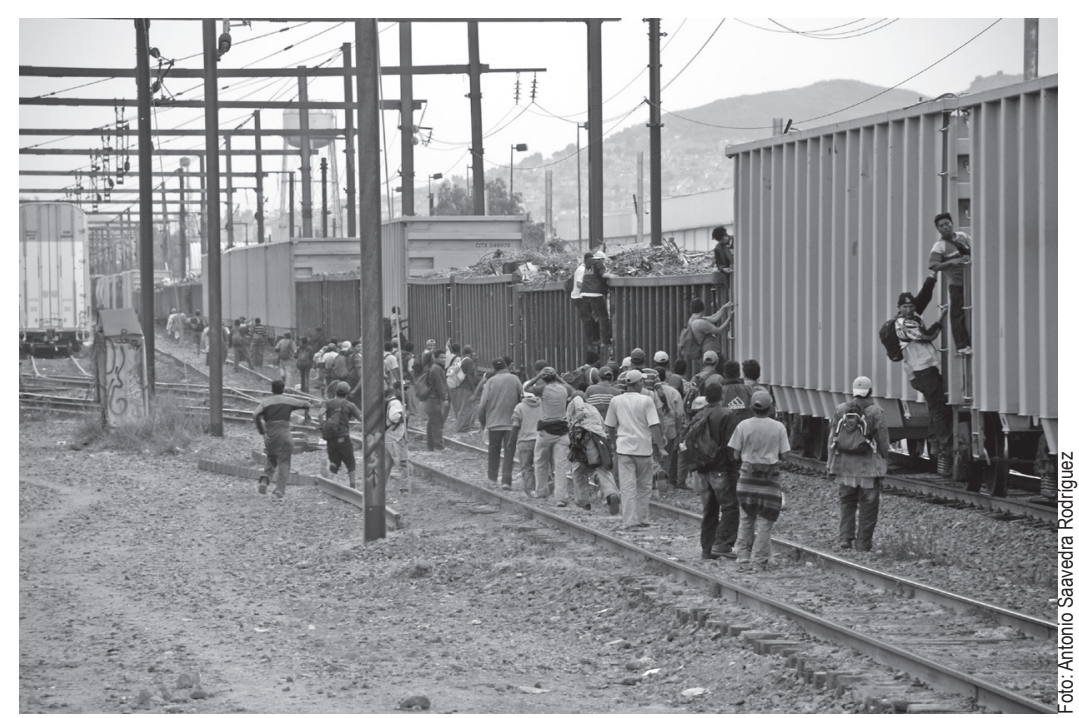

\section{Savĩa}

